\title{
ANÁLISE DE CLUSTERS: TÉCNICA DE AGRUPAMENTO, ARTE DE INTERPRETAÇÃO DOS RESULTADOS
}

\author{
Paulo Castro Ribeiro*
}

\section{INTRODUÇÃO}

São inúmeros os exemplos que podemos encontrar, na história do pensamento humano, sobre as formas de abordar o real tendo em vista a sua compreensão.

Alguns dos esforços mais profícuos surgem-nos na antiga Grécia. Entre outros, gostaríamos de salientar o contributo dado por Aristóteles na formulação da chamada Teoria da Abstracção, segundo a qual seria possível a formulação de conceitos. Aristóteles propõe-nos a utilização de uma faculdade da razão (a abstracção), como forma de separar o essencial do acessório, tendo em vista a formulação dos conceitos. É desta forma que concebemos árvore independentemente da sua espécie, cadeira independentemente da sua forma.

A formulação dos conceitos assenta em dois momentos distintos. O primeiro traduz-se no contacto com a diversidade do real através dos sentidos; o segundo naquela capacidade, própria dos seres racionais, que lhes permite reter e classificar o essencial como forma de o organizar.

Outro tipo de formulação é aquele que nos surge quando rotulamos um método científico de indutivo, dedutivo ou indutivo-dedutivo e vice-versa. Aqui dizemos que as etapas do método se encadeiam segundo uma ordem pré-determinada e bem estabelecida, fazendo a análise de um fenómeno do particular para o geral (método indutivo) ou do geral para o particular (método dedutivo).

Quer se trate duma ou doutra situação surge-nos sempre, em algum momento da investigação, a necessidade de agrupar e/ou classificar os indivíduos ${ }^{1}$ em análise que, no seu todo ou em parte, sustentarão as nossas conclusões.

Outras situações há em que a classificação ou agrupamento dos indivíduos é o próprio objectivo da pesquisa. Encontramos esta situação, por exemplo, na Taxinomia Numérica (Biologia), na Medicina, que utiliza técnicas de classificação para identificar tipologias de doenças e os seus diferentes estágios (o exame de vários

\footnotetext{
* Instituto Universitário de Desenvolvimento e Promoção Social — Pólo de Viseu da Universidade Católica Portuguesa.
} 
pacientes diagnosticados como depressivos permite-nos, numa análise mais aprofundada, verificar a existência de vários subgrupos de indivíduos com diferentes tipos de depressão), nos estudos de caracterização de populações e/ou regiões, na segmentação feita pelas empresas face ao seu mercado, etc. A aplicação desta técnica no âmbito da gestão, nomeadamente ao nível do marketing, tem vindo a vulgarizar-se e é aplicada sempre que se pretende fazer a classificação e agrupamento de indivíduos por forma a identificar grupos de pessoas com hábitos de consumo similares.

A técnica que iremos abordar neste artigo é conhecida como análise de clusters. Quer se trate de um instrumento intermédio de pesquisa ou de uma análise cujo objectivo final seja a constituição de grupos homogéneos de indivíduos, esta técnica revela-se como um instrumento bastante eficiente e de grande interesse ${ }^{2}$. Após a exposição desta técnica procuraremos indicar alguns dos seus campos de aplicação (ponto número 5), deixando desde já em aberto a necessidade de a conjugar, a montante, com a Análise Factorial de Componentes Principais e, a jusante, com os Testes de Hipótese de igualdade de duas médias ou de igualdade de $\mathrm{K}$ médias.

Um estudo realizado nos E.U.A. por Thomas C. Kinnear e Ann R. Root, em 1988, revelou que $49 \%$ das empresas americanas que têm departamento de marketing utilizam esta técnica nos seus estudos de mercado.

Passemos, então, a observar mais de perto, em que consiste e porque é que autores como Thomas C. Kinnear e James R. Taylor consideram a análise de clusters uma arte (Kinnear, T. e Taylor, J. ${ }^{4} 1991$ : 615).

\section{PRESSUPOSTOS DA ANÁLISE DE CLUSTERS:}

a) A análise de clusters permite ao investigador formar subgrupos de indivíduos $\left(\operatorname{casos}^{3}\right)$ ou variáveis;

b) Estes subgrupos (clusters) não são definidos a priori pelo investigador mas resultam da própria análise;

c) O agrupamento dos casos ou variáveis parte de uma matriz de associação que se traduz, habitualmente, numa matriz de distâncias/proximidades ou numa matriz de correlação;

d) Assume-se que qualquer conjunto de dados contém dentro de si subgrupos naturais.

Embora possamos definir clara e objectivamente todos os passos desta técnica, como veremos no exemplo que trataremos adiante, cabe ao investigador seleccionar o número de grupos desejado e, sobretudo, dar significado aos mesmos a partir da análise de cada observação ou variável pertencente a cada grupo. Neste artigo vamos centrar-nos numa análise essencialmente qualitativa (apelando fortemente à competência e sensibilidade do investigador), à falta de outros instru- 
mentos como sejam os Testes de Hipótese que nos podem, de forma objectiva, ajudar a significar os grupos constituídos.

Desta forma, podemos afirmar que esta técnica nos conduz à constituição de grupos, em que cada indivíduo de um mesmo grupo se encontra mais associado aos seus pares do que a qualquer outro indivíduo de outro grupo. No entanto, o significado profundo dessa associação deverá ser encontrado pelo investigador (fazendo uma análise do indivíduo para o grupo), através do maior (ou menor) conhecimento do fenómeno em análise.

Não fosse esta etapa suficiente para garantir à análise de clusters um cariz altamente personalizado, porque baseado nas competências e bom senso do seu artífice, poderíamos ainda aludir ao pressuposto d) que nos remete para um nível de abstracção suficiente para aceitarmos que, no mais diverso, podemos sempre encontrar partes cujo grau de associação é elevado. Por outro lado, Peter M. Chisnall (p. 317) afirma: "Cluster analysis (...) is not an analytical technique or single method, but a set of numerical methods in which are large areas of subjectivity, so researchers should proceed cautiously".

\section{APRESENTAÇÃO DA TÉCNICA PARA A CONSTITUIÇÃO DOS CLUSTERS:}

Para ilustrar esta técnica vamos utilizar um exemplo no qual se pretende formar grupos de indivíduos a partir de duas variáveis ${ }^{4}$ : Peso e Altura.

\section{Quadro 1}

Variáveis a partir das quais se pretende fazer 0 agrupamento dos indivíduos

\begin{tabular}{|c|c|c|}
\hline Indivíduos & Peso & Altura \\
\hline 1 & 95 & 1,95 \\
\hline 2 & 60 & 1,60 \\
\hline 3 & 92 & 1,68 \\
\hline 4 & 60 & 1,75 \\
\hline 5 & 62 & 1,72 \\
\hline 6 & 70 & 1,50 \\
\hline 7 & 68 & 1,70 \\
\hline 8 & 71 & 1,55 \\
\hline 9 & 50 & 1,60 \\
\hline 10 & 44 & 1,45 \\
\hline 11 & 45 & 1,50 \\
\hline 12 & 120 & 1,95 \\
\hline 13 & 95 & 1,70 \\
\hline 14 & 70 & 1,60 \\
\hline 15 & 85 & 1,70 \\
\hline 16 & 80 & 1,95 \\
\hline 17 & 80 & 1,78 \\
\hline 18 & 61 & 1,55 \\
\hline 19 & 48 & 1,55 \\
\hline 20 & 60 & 1,78 \\
\hline
\end{tabular}


Podemos representar a posição de cada indivíduo num sistema de eixos ortogonais e calcular a distância entre dois indivíduos calculando, por exemplo, a hipotenusa do triângulo definido pelos mesmos 5 .

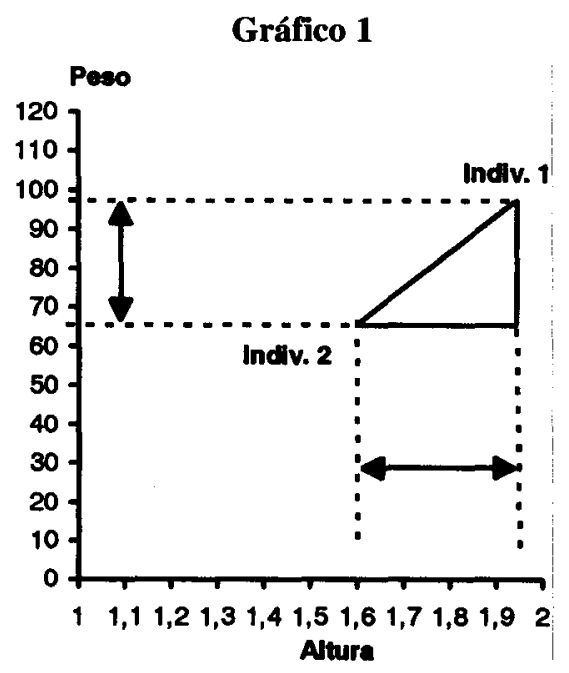

O cálculo da distância entre os indivíduos pode ser feito recorrendo a diferentes métricas ${ }^{6}$, das quais ilustraremos as seguintes:

a) Distância Euclidiana

$$
d_{i j}=\sqrt{\sum_{v=1}^{p}\left(\chi_{v j}-\chi_{v i}\right)^{2}}
$$

A distância entre dois indivíduos é dada pela raiz quadrada da soma do quadrado das diferenças dos valores de cada variável. Esta é a medida mais utilizada neste tipo de técnica, quando os valores das variáveis se encontram suficientemente dispersos e com uma boa amplitude. Corresponde, no gráfico 1, ao comprimento da hipotenusa.

b) Distância Euclidiana ao quadrado

$$
d^{2}{ }_{i j}=\sum_{v=1}^{p}\left(\chi_{v j}-\chi_{v i}\right)^{2}
$$

Utiliza-se quando pretendemos ampliar os valores das observações. A distância entre dois indivíduos é a soma do quadrado das diferenças dos valores de cada 106 variável. 
c) City-Block Metria

$$
d_{i j}=\sum_{v=1}^{p}\left|\chi_{v j}-\chi_{v i}\right|
$$

A distância entre dois indivíduos corresponde à soma da diferença absoluta de cada variável. Corresponde, no gráfico 1 , à soma dos comprimentos dos catetos.

d) Distância de Chebychev

$$
d_{i j}=\max _{v}\left|\chi_{v j}-\chi_{v i}\right|
$$

A distância entre dois indivíduos é dada pela maior diferença absoluta em valor para qualquer variável. Corresponde, no gráfico 1, ao comprimento do cateto mais longo.

e) Distância de Minkowski

$$
d_{i j}=\left(\sum_{\nu=1}^{p}\left|\chi_{v j}-\chi_{v i}\right|^{r}\right)^{\frac{1}{r}}
$$

A distância entre dois indivíduos é a soma da diferença absoluta elevada a $\mathrm{r}$, elevada a 1/r. Inclui a distância euclidiana para o caso especial de r=2.

No nosso exemplo utilizaremos a métrica euclidiana. Assim, a distância entre o $1 .^{\circ}$ e o $2 .^{\circ}$ indivíduo será:

$$
\begin{aligned}
& d_{(1,2)}=\sqrt{(1,95-1,60)^{2}+(95-60)^{2}} \\
& d_{(1,2)}=\sqrt{1225,95-1,60)} \\
& d_{(1,2)}=35,0018
\end{aligned}
$$

Após o cálculo das distâncias entre todos os indivíduos chegamos aos resultados que apresentamos na figura 1 (1. ${ }^{\mathrm{a}}$ matriz de distâncias). 


\section{Figura 1}

1. ${ }^{\text {a }}$ Matriz de distâncias

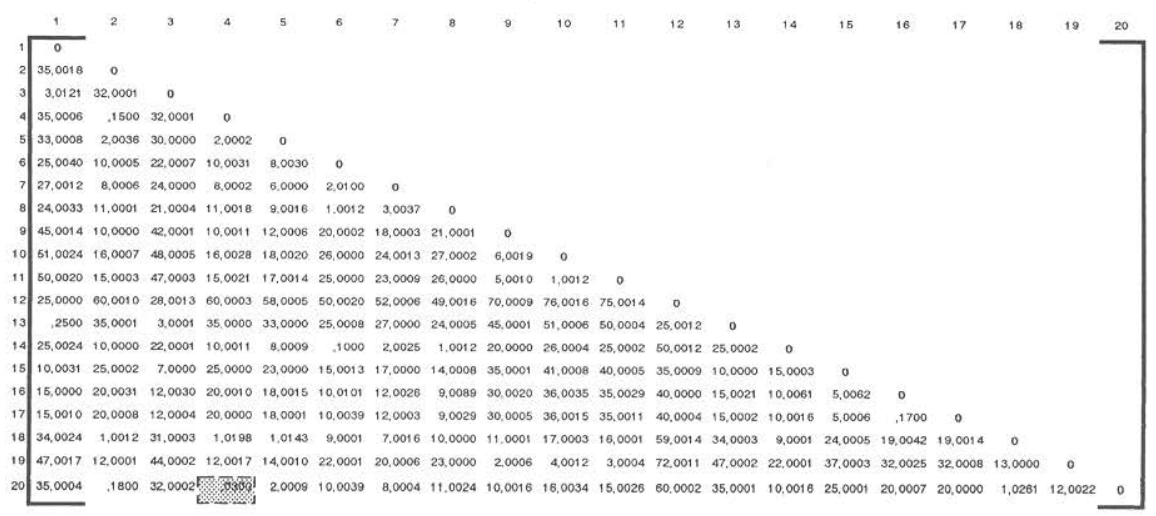

Estamos em presença de uma matriz simétrica, como se percebe facilmente, porque a distância a qualquer indivíduo i e outro j é necessariamente igual à distância entre je i.

A partir desta matriz podemos começar a agrupar os indivíduos (agrupando em primeiro lugar aqueles que apresentarem menor distância). Trata-se, portanto, de encontrar na matriz de distâncias o menor valor e, depois, saber quais os indivíduos ou grupos que the correspondem, fazendo a leitura na $1 .^{\mathrm{a}}$ linha e $1 .{ }^{\mathrm{a}}$ coluna. Após a constituição do grupo, surge um novo problema: como avaliar a distância de um grupo ou indivíduo a outro grupo ou a outro indivíduo? Para este fim utiliza-se um dos critérios que expomos de seguida (Voltaremos ao nosso exemplo adiante).

\section{Critérios para o cálculo da distância:}

a) Vizinho mais próximo (nearest neighbor / single linkage);

Exemplo de recálculo de distâncias após agrupamento:

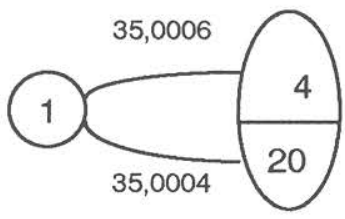

De acordo com este critério, a distância entre 1 e o grupo $(4,20)$ será 35,0004 .

Este método é eficiente do ponto de vista do cálculo mas tende a produzir clus108 ters de tipo "cobra"? 
b) Vizinho mais afastado (furthest neighbor / complete linkage);

Exemplo de recálculo de distâncias após agrupamento:

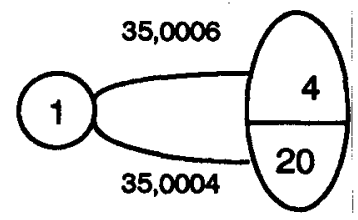

De acordo com este critério, a distância entre 1 e o grupo $(4,20)$ será 35,0006 .

Utilizando este método de agrupamento, conseguem-se as vantagens de cálculo do anterior mas produzem-se clusters mais equilibrados. Lehmann (p. 629) advoga ser este o método mais indicado no âmbito dos estudos de mercado. Este método, ao contrário do anterior, vai "empurrando" os indivíduos mais próximos para agrupamentos futuros, permitindo um maior equilíbrio entre os grupos que se vão formando.

c) Média entre grupos (Average between groups).

Exemplo de recálculo de distâncias após agrupamento:

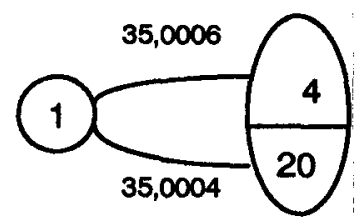

De acordo com este critério, a distância entre 1 e o grupo $(4,20)$ será 35,0005 .

Este critério de agrupamento tende a normalizar a estrutura inicial dos dados, fazendo com que os valores extremos sejam mais facilmante agrupados.

\section{d) Centroide}

A utilização deste método, bem como de todos os demais que nele se baseiam ${ }^{8}$, requer um acréscimo à capacidade de cálculo, uma vez que se torna necessário obter o indivíduo médio do grupo - calculando a média das coordenadas dos indivíduos do grupo. Depois de encontrados os valores médios, calcula-se a distância ao indivíduo ou grupo a agrupar, utilizando a distância euclidiana ao quadrado.

No nosso exemplo teríamos:

a) Cálculo dos valores médios das coordenadas dos indivíduos do grupo $(4,20)$;

\begin{tabular}{|c|c|c|}
\hline Indivíduos & Peso & Altura \\
\hline 1 & 95 & 1,95 \\
\hline 4,20 & 60 & 1,765 \\
\hline
\end{tabular}


b) Cálculo da distância entre o indivíduo 1 e o indivíduo médio do grupo (4,20):

$$
\begin{aligned}
& d_{(1),(4,20)}^{2}=\sqrt{(1,95-1,765)^{2}+(95-60)^{2}} \\
& d_{(1),(4,20)}=33,54153
\end{aligned}
$$

Qualquer que seja o critério de agrupamento adoptado, devem ser observadas as seguintes etapas:

\section{Figura 1.1}

\section{Etapas para o agrupamento dos indivíduos}

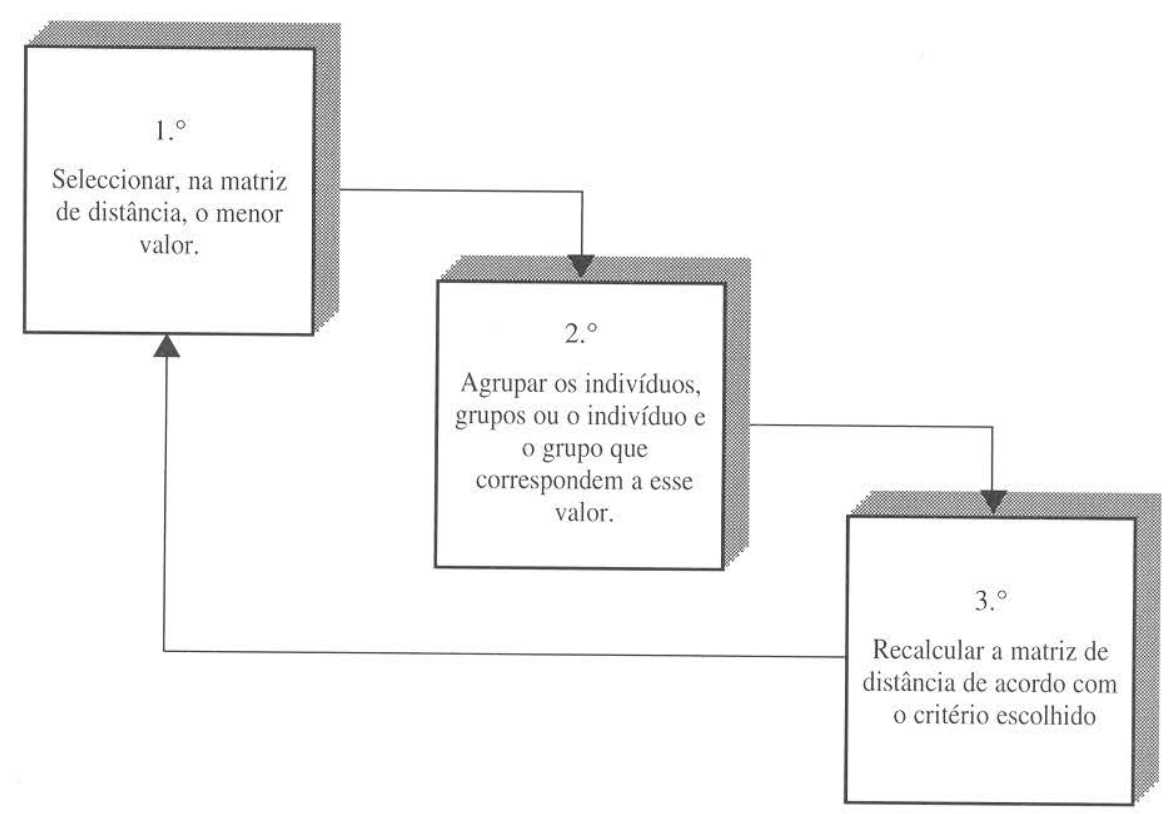

De regresso ao nosso exemplo podemos verificar, na matriz de distâncias, que o par de indivíduos que apresentam menor distância são o 4 e o 20, com 0,0300. Estes dois indivíduos constituirão o primeiro grupo $(4,20)$. Após o agrupamento temos que recalcular a matriz de distâncias. Vamos utilizar, a título exemplifica110 tivo, o critério da média entre grupos. 


\title{
Figura 2
}

\author{
2. ${ }^{a}$ matriz de distâncias
}

\section{Recálculo para o $1 .^{\circ}$ Agrupamento - Critério $\rightarrow$ Média entre grupos}

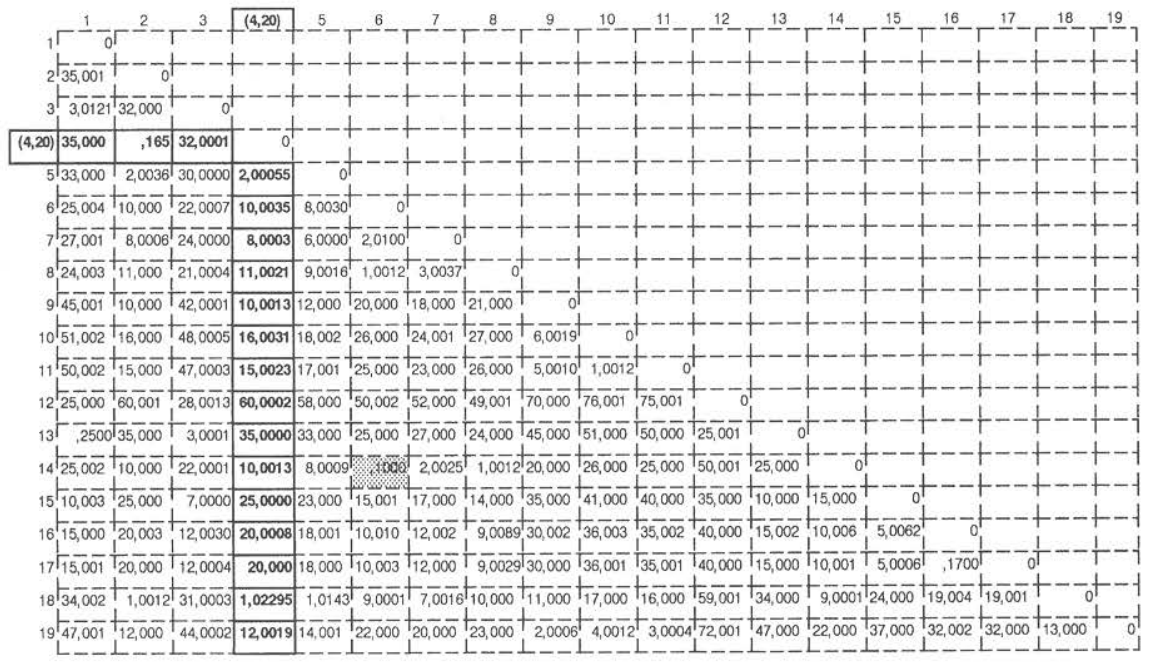

Para sistematizar a informação vamos elaborar um quadro, como o que se apresenta de seguida, onde colocaremos o passo, a distância à qual foi feito o último agrupamento e os grupos constituídos.

\section{Tabela 1}

\section{1. ${ }^{\circ}$ Quadro-síntese}

\begin{tabular}{|c|c|c|}
\hline Passo & Distância & Grupos \\
\hline 1 & $d_{4,20}=0,03$ & $1,2,3,(4,20), 5,6,7,8,9,10,11,12,13,14,15,16,17,18,19$ \\
\hline
\end{tabular}

Após o primeiro agrupamento, verificamos, na matriz anterior, que o par de indivíduos que agora se encontram à menor distância são o 6 e o 14, a uma distância de 0,1000. Vamos, então, recalcular a matriz de distâncias, em função do grupo a formar, definido na matriz anterior, e assinalar na matriz recalculada qual será o próximo grupo, ou seja, os indivíduos ou grupos de indivíduos que se encontrem à menor distância. 
Figura 3

3. ${ }^{\mathrm{a}}$ matriz de distâncias

\section{Recálculo para o 2. ${ }^{\circ}$ Agrupamento - Critério $\rightarrow$ Média entre grupos}

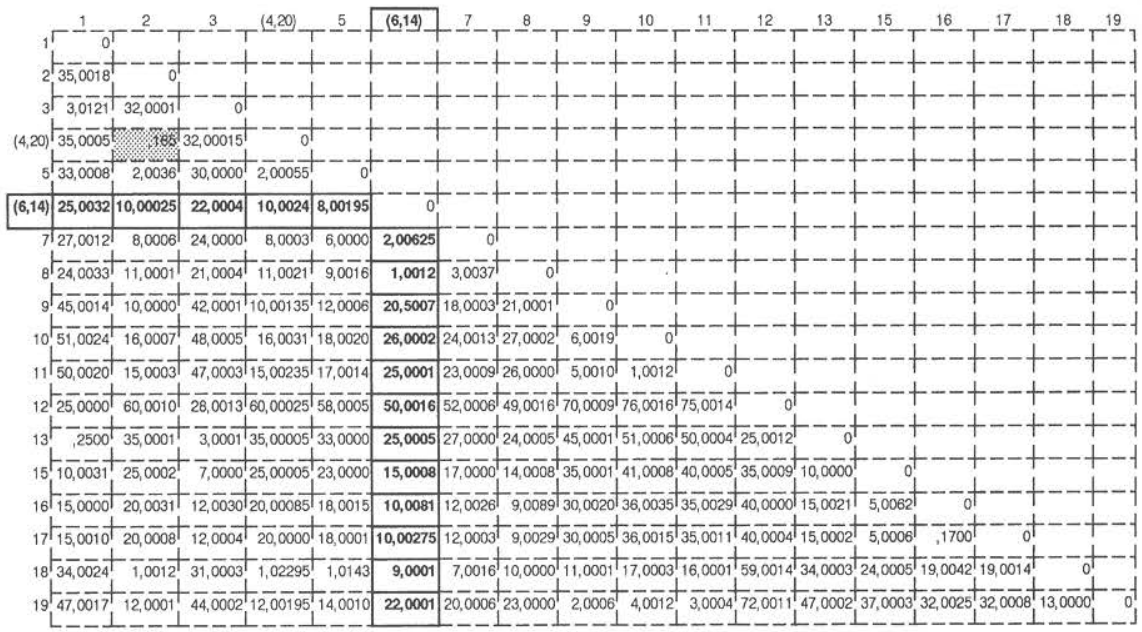

Tabela 2

\section{2. ${ }^{\circ}$ Quadro-síntese}

\begin{tabular}{|c|c|c|}
\hline Passo & Distância & Grupos \\
\hline 1 & $d_{4,20}=0,03$ & $1,2,3,(4,20), 5,6,7,8,9,10,11,12,13,14,15,16,17,18,19$ \\
\hline 2 & $d_{6,14}=0,1$ & $1,2,3,(4,20), 5,(6,14), 7,8,9,10,11,12,13,15,16,17,18,19$ \\
\hline
\end{tabular}

O grupo $(4,20)$ e o indivíduo 2 são os que se encontram à menor distância, como podemos verificar na matriz anterior. O próximo grupo será, então, constituído pelos indivíduos $(4,20,2)$. O recálculo desta e das demais matrizes, até que todos os indivíduos se encontrem agrupados num único grupo, exceptuando o último agrupamento, encontram-se no anexo II.

A 18. ${ }^{a}$ matriz correspondente ao $17 .^{\circ}$ agrupamento e apresenta-se de seguida. Podemos verificar que este é o último passo a dar em termos de agrupamentos porque, após o mesmo, ficamos apenas com um único grupo (composto por todos os indivíduos), onde o indivíduo 12 é agrupado aos demais a uma distância de 48,0011 . 
Figura 4

18. ${ }^{a}$ matriz de distâncias

Recálculo para o 17. Agrupamento - Critério $\rightarrow$ Média entre grupos

\begin{tabular}{|c|c|c|}
\hline & $(1,13,3,16,17,15),(4,20,2,18,5,6,14,8,7,9,19,10,11)$ & 12 \\
\hline$(1,13,3,16,17,15),(4,20,2,18,5,6,14,8,7,9,19,10,11)$ & 更 & \\
\hline 12 & 48,0011 & \\
\hline
\end{tabular}

Tabela 3

18. ${ }^{\circ}$ Quadro Síntese

\begin{tabular}{|c|c|c|c|}
\hline Linha $^{9}$ & Passo & Distância & Grupos \\
\hline 19 & 1 & $d_{4,20}=0,03$ & $1,2,3,(4,20), 5,6,7,8,9,10,11,12,13,14,15,16,17,18,19$ \\
\hline 18 & 2 & $\mathrm{~d}_{6,14}=0,1$ & $1,2,3,(4,20), 5,(6,14), 7,8,9,10,11,12,13,15,16,17,18,19$ \\
\hline 17 & 3 & $d_{(4,20), 2=0,165}$ & $1,(4,20,2), 3,5,(6,14), 7,8,9,10,11,12,13,15,16,17,18,19$ \\
\hline 16 & 4 & $\mathrm{~d}_{(16,172=0,17}$ & $1,(4,20,2), 3,5,(6,14), 7,8,9,10,11,12,13,15,(16,17), 18,19$ \\
\hline 15 & 5 & $\mathrm{~d}_{(1,13)=0,25}$ & $(1,13),(4,20,2), 3,5,(6,14), 7,8,9,10,11,12,15,(16,17), 18,19$ \\
\hline 14 & 6 & $d_{(1011)}=1,0012$ & $(1,13),(4,20,2), 3,5,(6,14), 7,8,9,(10,11), 12,15,(16,17), 18,19$ \\
\hline 13 & 7 & $\mathrm{~d}_{(6,14), \mathrm{a}}=1,0012$ & $(1,13),(4,20,2), 3,5,(6,14,8), 7,9,(10,11), 12,15,(16,17), 18,19$ \\
\hline 12 & 8 & $\mathrm{~d}_{(4,20,2): 18}=1,0121$ & $(1,13),(4,20,2,18), 3,5,(6,14,8), 7,9,(10,11), 12,15,(16,17), 19$ \\
\hline 11 & 9 & $d_{(4,20,318), 5}=1,5082$ & $(1,13),(4,20,2,18,5), 3,(6,14,8), 7,9,(10,11), 12,15,(16,17), 19$ \\
\hline 10 & 10 & $\mathrm{~d}_{\mathrm{g}(\mathrm{g}, \mathrm{n}}=2,0006$ & $(1,13),(4,20,2,18,5), 3,(6,14,8), 7,(9,19),(10,11), 12,15,(16,17)$ \\
\hline 9 & 11 & $d_{(5,402,7}=2,505$ & $(1,13),(4,20,2,18,5), 3,(6,14,8,7),(9,19),(10,11), 12,15,(16,17)$ \\
\hline 8 & 12 & $d_{(1,13), 3}=3,0061$ & $(1,13,3),(4,20,2,18,5),(6,14,8,7),(9,19),(10,11), 12,15,(16,17)$ \\
\hline 7 & 13 & $d_{(9,19)(10,11)}=4,5012$ & $(1,13,3),(4,20,2,18,5),(6,14,8,7),(9,19,10,11), 12,15,(16,17)$ \\
\hline 6 & 14 & $d_{(16,17), 15=5,0034}$ & $(1,13,3),(4,20,2,18,5),(6,14,8,7),(9,19,10,11), 12,(16,17,15)$ \\
\hline 5 & 15 & $d_{44,20,218,56614,872}=8,001$ & $(1,13,3),(4,20,2,18,5,6,14,8,7) \cdot(9,19,10,11), 12,(16,17,15)$ \\
\hline 4 & 16 & $d_{(1,133),(16,12,16)=11,5011}$ & $(1,13,3,16,17,15),(4,20,2,18,5,6,14,8,7),(9,19,10,11), 12$ \\
\hline 3 & 17 & 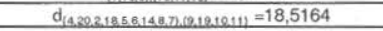 & $(1,13,3,16,17,15),(4,20,2,18,5,6,14,8,7,9,19,10,11), 12$ \\
\hline 2 & 18 & $d_{(1.13,318,215)(4,20,2185.61487,918,011)}=32,001$ & $(1,13,3,16,17,15,4,20,2,18,5,6,14,8,7,9,19,10,11), 12$ \\
\hline 1 & 19 & $\mathrm{~d}_{(1,13,3,16,17,15,4,20,3,18,5,8,4,8,7,19,10,11), 12}=48.0011$ & $(1,2,3,4,5,6,7,8,9,10,11,12,13,14,15,16,17,18,19,20)$ \\
\hline
\end{tabular}

\section{ANÁLISE DOS RESULTADOS:}

Terminado o processo de constituição dos grupos, podemos verificar no quadro anterior que os indivíduos mais próximos são o 4 e o 20, a uma distância de 0,03. À medida que a distância vai aumentando, novos grupos se vão formando ou grupos já formados vão alargando o seu efectivo. Este processo culmina com a constituição de um único grupo que reúne todos os indivíduos, no nosso exemplo, a uma distância de 48,0011.

A leitura deste último quadro-síntese fornece-nos todos os elementos de que necessitamos para analisar os grupos constituídos; todavia, essa leitura não se torna muito acessível. Por isso apresentamos, de seguida, as duas ferramentas mais utilizadas, para facilitar a interpretação destes resultados, tendo em vista a tomada de decisão sobre o número de clusters a reter.

\section{a) O gráfico Icicle}

Neste gráfico os indivíduos, observações ou casos são representados em coluna e o número de grupos é representado em linha. A primeira coluna representa o 
último indivíduo a ser agrupado e a última coluna representa o primeiro indivíduo a ser agrupado. As linhas representam os passos dados ao longo do processo de agrupamento.

O gráfico deve ser lido de baixo para cima. A última linha do gráfico representa o primeiro passo do agrupamento e a primeira linha representa o último passo, onde todos os indivíduos se encontram agrupados num único grupo. Geralmente não se representa o passo zero (seria a linha 20 do gráfico), onde todos os indivíduos se encontrariam separados e, consequentemente, o número de grupos seria igual ao número de indivíduos (no nosso exemplo 20). Os números das linhas representam o número de grupos formados.

Neste gráfico, cada indivíduo é representado por uma coluna que é separada das demais por uma coluna em branco. À medida que os indivíduos vão sendo agrupados, a coluna em branco, que os separa, desaparece. Através deste gráfico, pode-se ensaiar a constituição de diferentes clusters em função do número de grupos que se selecciona na primeira coluna, cortando o gráfico horizontalmente.

\section{Gráfico 2}

Icicle

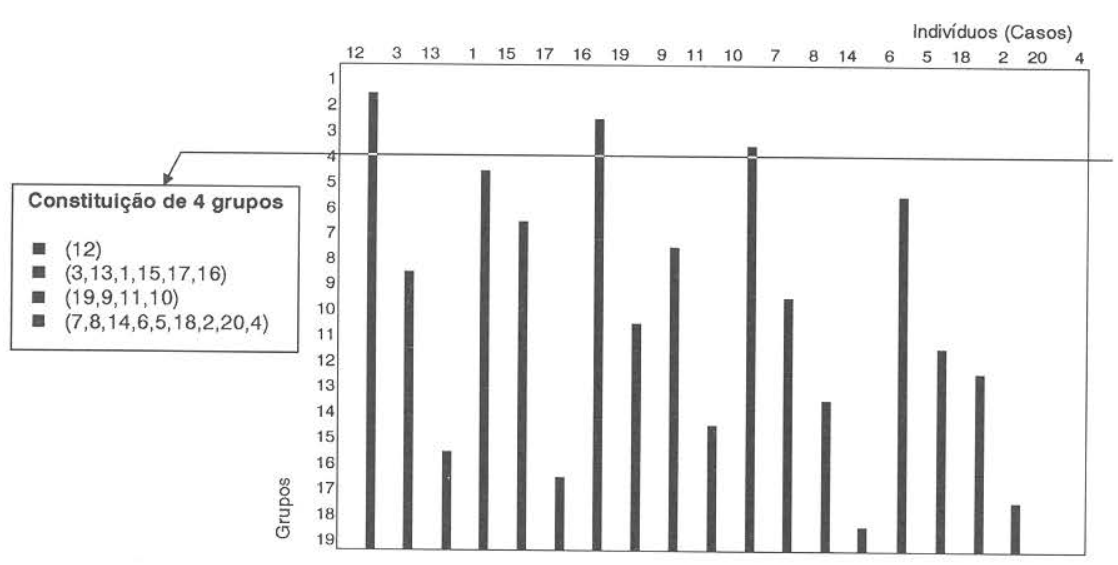

\section{b) O Dendrograma}

A outra forma de visualização dos resultados da análise de clusters é o dendrograma. Neste gráfico podemos identificar a forma como os grupos vão sendo formados e os valores dos respectivos coeficientes para cada passo.

Enquanto no Icicle partimos do número de grupos que se pretende constituir, 114 embora não saibamos nada sobre a distância a que estes se formam, no dendro- 
grama partimos da distância desejada entre os grupos e, de seguida, vamos saber quantos grupos se formam àquela distância e quem são os indivíduos que compõem esses grupos.

No dendrograma encontramos os indivíduos em linha e em coluna as distâncias. Habitualmente as distâncias representadas no dendrograma vão até 25 , sendo as distâncias reais (aquelas às quais foram constituídos os grupos) recalculadas para este valor máximo ${ }^{10}$.

O dendrograma deve ser cortado na vertical, à distância pretendida, e de seguida deve-se verificar o número de grupos formados, bem como os indivíduos pertencentes a cada grupo.

\section{Gráfico 3 \\ Dendrograma}

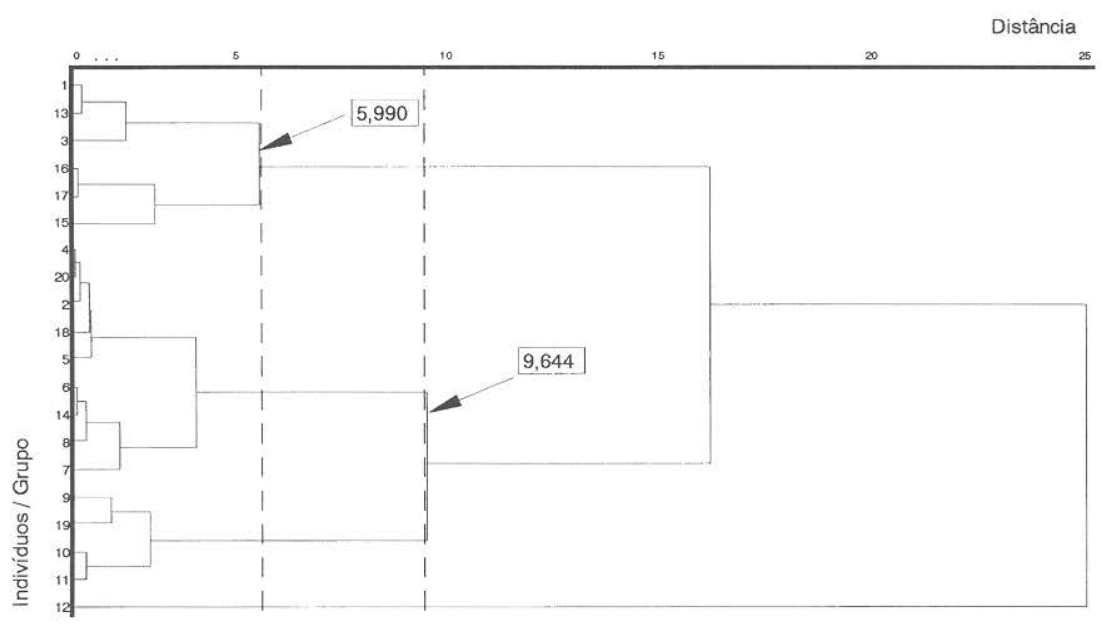

Se cortarmos o dendrograma a uma distância superior a 5,990 e inferior a 9,644, ficamos com 4 grupos de indivíduos. Assim sendo, um dos grupos é formado pelos indivíduos $1,3,13,15,16$ e 17 ; outro é formado pelos indivíduos $2,4,5,6,7,8,14,18$ e 20; outro formado por 9,10,11 e 19; e o último grupo formado por um único indivíduo, o $\mathrm{n}^{\circ} 12$.

Fazendo uma análise qualitativa destes grupos, podemos afirmar o seguinte:

- O grupo $(1,3,13,15,16,17)$ é caracterizado por ser constituído por indivíduos com pesos compreendidos entre [80-95] Kg e alturas compreendidas entre $[1,68-1,95] \mathrm{m}$;

- O grupo $(2,4,5,6,7,8,14,18,20)$ é caracterizado por ser constituído por indivíduos com pesos compreendidos entre [60-71] Kg e alturas compreendidas entre $[1,68-1,95] \mathrm{m}$; 
- O grupo $(9,10,11,19)$ é caracterizado por ser constituído por indivíduos com pesos compreendidos entre [44-50] $\mathrm{Kg}$ e alturas compreendidas entre [1,45$-1,60] \mathrm{m}$;

- O grupo constituído pelo indivíduo 12 caracteriza-se por ter o peso de $120 \mathrm{Kg}$ e altura de $1,95 \mathrm{~m}$.

\section{CONSIDERAÇÕES FINAIS:}

A análise de clusters, como tivemos ocasião de referir anteriormente, é uma técnica que pode ser posta ao serviço das várias ciências. No entanto, para aquilo que nos interessa, torna-se agora oportuno tecer algumas considerações sobre a aplicação desta técnica, conjugada com outros instrumentos de análise, no âmbito da gestão.

A título meramente indicativo podemos sugerir os seguintes campos de aplicação:

a) Caracterização de uma população-alvo ao nível de estudos exploratórios e/ou conclusivos tendo em vista, por exemplo, a implementação de uma nova indústria, um reposicionamento estratégico, o lançamento de um novo produto, etc;

b) Segmentação do mercado a partir do conhecimento dos traços característicos de cada grupo de consumidores;

c) Caracterização da oferta tendo em vista, por exemplo, a constituição de grupos estratégicos, detecção de sinergias, etc;

d) Construção de perfis profissionais, melhor adequação entre qualificações e especificações do posto de trabalho, etc;

Estes são alguns exemplos, na área da gestão, onde a aplicação desta técnica, conjugada com outros instrumentos de análise - nomeadamente a Análise Factorial de Componentes Principais e os Testes de Hipótese - se mostra de grande valia.

Gostaríamos, no entanto, de referir que a análise de clusters, de per si, não nos fornece respostas objectivas sobre o significado dos grupos constituídos. É aqui que se torna essencial a utilização dos testes de hipótese de igualdade de médias (o teste $T$, para a igualdade de duas médias e o teste de análise de variância ${ }^{11}$, para a igualdade de mais do que duas médias), para que se possa saber a que níveis os grupos formados são iguais ou diferentes. A aceitação ou rejeição das hipóteses que formulármos para as diferentes variáveis a testar (necessariamente relevantes do ponto de vista do estudo em causa), em função dos grupos constituídos, a priori pela análise de clusters, vai-nos permitir caracterizar cada um desses grupos.

Por outro lado, a criação dos grupos, através da análise de clusters, tornar-se-á tanto mais interessante quanto maior for a quantidade de informação existente para a constituição desses grupos. É nesta perspectiva que habitualmente se uti- 
liza a Análise Factorial de Componentes Principais (AFCP), como técnica que nos fornecerá os inputs para a constituição dos clusters. Através da AFCP conseguimos reduzir o número de variáveis em análise, que passam a ser bem representadas pelos factores constituídos. Os Factores criados devem explicar uma percentagem elevada da variância das variáveis que agregam e sugerir o significado dessa agregação. São estes Factores ou Componentes Principais que vão alimentar a análise de Clusters.

No fim deste artigo ficamos com a sensação de termos começado a obra pelo meio. Esta sensação é minorada pelo facto de a técnica apresentada poder constituir, por si só, uma unidade de análise de dados. Fica, no entanto, a promessa de no futuro voltarmos a este assunto, abordando a Análise Factorial de Componentes Principais e os Testes de Hipótese referidos.

\section{NOTAS}

1 Tomamos por indivíduo: seres, objectos, um conjunto de características, etc.

2 Registe-se, a este propósito, que a análise de clusters é, a maior parte das vezes, utilizada como técnica intermédia. Com isto queremos dizer que, habitualmente, os inputs da análise de clusters não são variáveis simples mas componentes principais (resultantes da análise factorial de componentes principais). Por outro lado, os grupos construídos pela análise de clusters são testados e ganham significado através da aplicação, aos diferentes grupos, de testes de hipótese (sejam eles de duas ou mais médias). Através deles verifica-se se, por exemplo, a importância média dada a determinada componente principal é igual em ambos os sexos (teste de igualdade de duas médias) ou, se a importância média dada a determinada componente principal é igual nos diferentes grupos (teste de igualdade de $\mathrm{K}$ médias).

${ }^{3}$ Utilizamos o termo casos, como sinónimo de observações ou indivíduos por ser esta a terminologia utlizada ao nível do "software" estatístico, nomeadamente pelo SPSS (Statistical Package for the Social Sciences).

${ }^{4} \mathrm{O}$ exemplo que iremos utilizar tem por único objectivo ilustrar esta técnica. Refira-se, ainda, que vários autores, entre os quais Lehmann, ${ }^{3} 1989$ (p. 639), referem que a análise de clusters só deve ser feita para um conjunto de dados que contenham, pelo menos, 30 observações (casos). Daqui retira-se, habitualmente, a regra de constituir 1 cluster por cada 30 indivíduos, ou seja, o número de clusters a constituir deverá andar perto de $\mathrm{n} / 30$.

${ }^{5}$ Recordemos o teorema de Pitágoras: "O quadrado da hipotenusa é igual á soma do quadrado dos catetos."

${ }^{6}$ Estes são os métodos de cálculo utilizados pelo SPSS. Veja-se, a este respeito, a melhor adequação entre o método de cálculo das distâncias e o método de agrupamento a utilizar em: NORUSIS, Marija J., SPSS Professional Statistics, SPSS inc.

${ }^{7}$ Esta terminologia é utilizada por Lehmann, Market Research and Analysis, ${ }^{3} 1989$ (p. 629)

${ }^{8}$ Referimo-nos, especificamente, ao método de Ward e ao método da Mediana que não desenvolveremos neste artigo por se tratar de métodos baseados nos Centroides.

${ }^{9}$ Invertemos a numeração dos passos para facilitar a compreensão do gráfico Icicle.

${ }^{10}$ Este procedimento justifica-se na medida em que, a partir dos novos valores (relativos), é possível estabelecer comparações entre diferentes dendrogramas resultantes de diversas análises de clusters.

11 Embora o SPSS chame este teste de análise de variância, trata-se de um teste de igualdade de mais do que duas médias apoiado na distribuição $\mathrm{F}$ de Snedcor. 


\section{BIBLIOGRAFIA}

CHISNALL, Peter M., ${ }^{3} 1986$, Marketing Research, McGraw-Hill Book Company (UK) Limited.

HAIR, JOSEPH F. et al., ${ }^{4} 1995$, Multiuariate data Analysis, Prentice Hall, New Jersey.

LEHMANN, Donald R., ${ }^{3} 1989$, Market Research and Analysis, IRWIN:Boston

KINNEAR, T. e Taylor, J., ${ }^{4} 1991$, Marketing Research, An applied approach, McGrawHill:International Editions.

NORUSIS, Marija J., 1992, SPSS Base System Users Guide, SPSS inc.

NORUSIS, Marija J., 1992, SPSS Professional Statistics, SPSS inc.

REIS, Elizabeth e MOREIRA, Raúl, 1993, Pesquisa de Mercado, Lisboa, Ed. Sílabo.

\section{ANEXOS}

\section{3. ${ }^{a}$ MATRIZ DE DISTÂNCIAS}

\section{Recálculo para o 2..$^{\circ}$ Agrupamento - Critério $\rightarrow$ Média entre grupos}

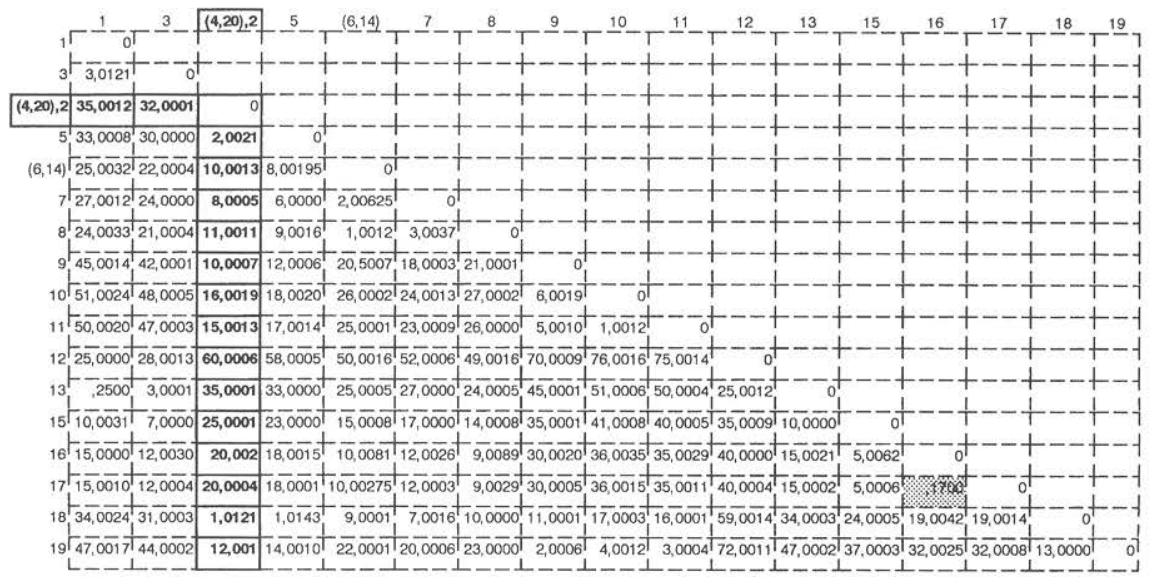

\section{3. ${ }^{\circ}$ Quadro-síntese}

\begin{tabular}{|c|c|c|}
\hline Passo & Distância & Grupos \\
\hline 1 & $\mathrm{~d}_{4,20}=0,03$ & $1,2,3,(4,20), 5,6,7,8,9,10,11,12,13,14,15,16,17,18,19$ \\
\hline 2 & $\mathrm{~d}_{6,14}=0,1$ & $1,2,3,(4,20), 5,(6,14), 7,8,9,10,11,12,13,15,16,17,18,19$ \\
\hline 3 & $\mathrm{~d}_{(4,20), 2}=0,165$ & $1,(4,20,2), 3,5,(6,14), 7,8,9,10,11,12,13,15,16,17,18,19$ \\
\hline
\end{tabular}




\section{4. ${ }^{a}$ MATRIZ DE DISTÂNCIAS}

\section{Recálculo para o 3 . $^{\circ}$ Agrupamento - Critério $\rightarrow$ Média entre grupos}

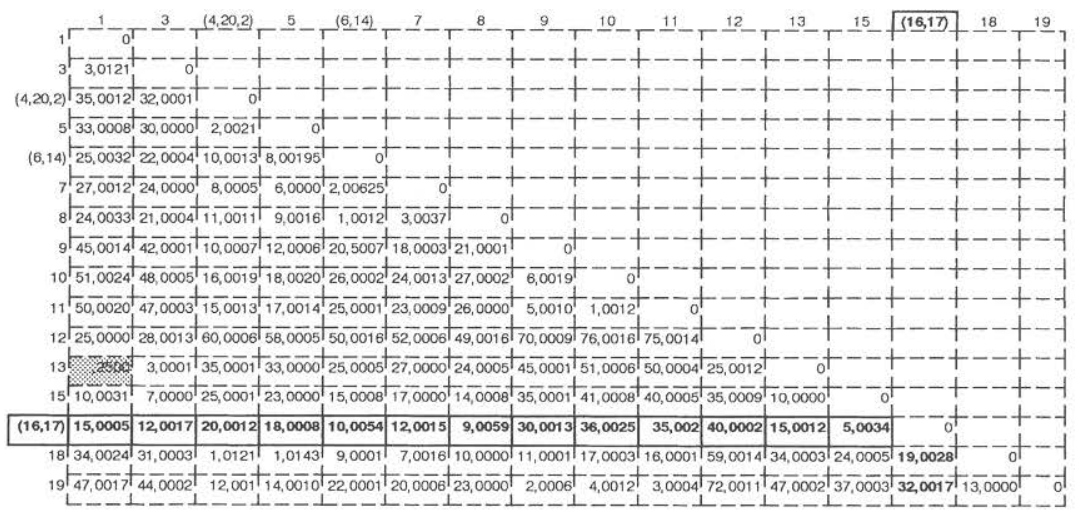

\section{4. ${ }^{\circ}$ Quadro -síntese}

\begin{tabular}{|c|c|c|}
\hline Passo & Distância & Grupos \\
\hline 1 & $\mathrm{~d}_{4,20}=0,03$ & $1,2,3,(4,20), 5,6,7,8,9,10,11,12,13,14,15,16,17,18,19$ \\
\hline 2 & $\mathrm{~d}_{6,14}=0,1$ & $1,2,3,(4,20), 5,(6,14), 7,8,9,10,11,12,13,15,16,17,18,19$ \\
\hline 3 & $\mathrm{~d}_{(4,20), 2}=0,165$ & $1,(4,20,2), 3,5,(6,14), 7,8,9,10,11,12,13,15,16,17,18,19$ \\
\hline 4 & $\mathrm{~d}_{(16,17)}=0,17$ & $1,(4,20,2), 3,5,(6,14), 7,8,9,10,11,12,13,15,(16,17), 18,19$ \\
\hline
\end{tabular}

\section{MATRIZ DE DISTÂNCIAS}

\section{Recálculo para o $4 .^{\circ}$ Agrupamento - Critério $\rightarrow$ Média entre grupos}

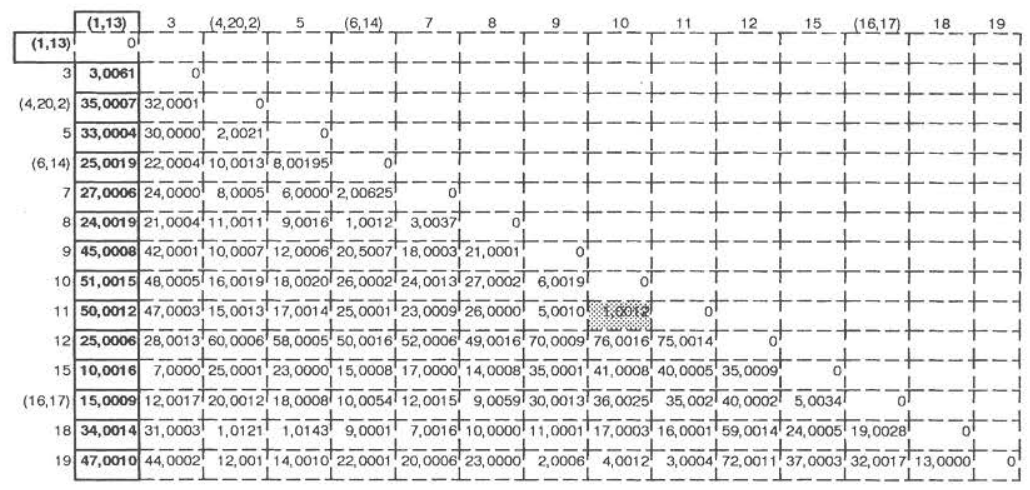




\section{6. ${ }^{\text {a }}$ MATRIZ DE DISTÂNCIAS}

\section{Recálculo para o $5 .^{\circ}$ Agrupamento — Critério $\rightarrow$ Média entre grupos}

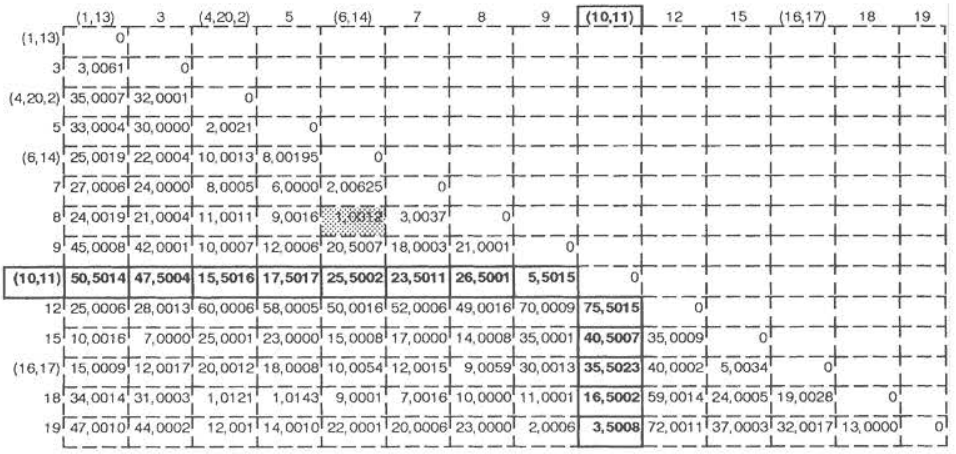

\section{6. ${ }^{\circ}$ Quadro-síntese}

\begin{tabular}{|c|c|c|}
\hline Passo & Distância & Grupos \\
\hline 1 & $\mathrm{~d}_{4,20}=0,03$ & $1,2,3,(4,20), 5,6,7,8,9,10,11,12,13,14,15,16,17,18,19$ \\
\hline 2 & $\mathrm{~d}_{6,14}=0,1$ & $1,2,3,(4,20), 5,(6,14), 7,8,9,10,11,12,13,15,16,17,18,19$ \\
\hline 3 & $\mathrm{~d}_{(4,20), 2}=0,165$ & $1,(4,20,2), 3,5,(6,14), 7,8,9,10,11,12,13,15,16,17,18,19$ \\
\hline 4 & $\mathrm{~d}_{(16,17)}=0,17$ & $1,(4,20,2), 3,5,(6,14), 7,8,9,10,11,12,13,15,(16,17), 18,19$ \\
\hline 5 & $\mathrm{~d}_{(1,13)}=0,25$ & $(1,13),(4,20,2), 3,5,(6,14), 7,8,9,10,11,12,15,(16,17), 18,19$ \\
\hline 6 & $\mathrm{~d}_{(10,11)}=1,0012$ & $(1,13),(4,20,2), 3,5,(6,14), 7,8,9,(10,11), 12,15,(16,17), 18,19$ \\
\hline
\end{tabular}

\section{7. ${ }^{\mathrm{a}}$ MATRIZ DE DISTÂNCIAS}

\section{Recálculo para o $6 .^{\circ}$ Agrupamento - Critério $\rightarrow$ Média entre grupos}

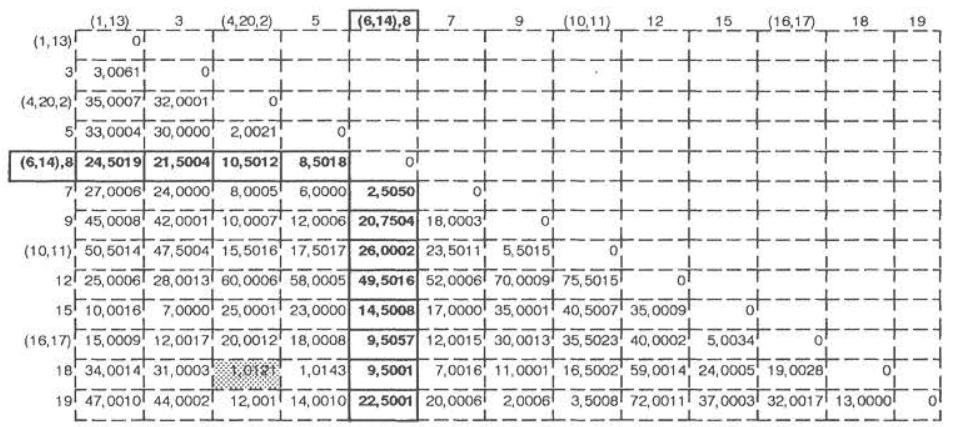

\section{7. ${ }^{\circ}$ Quadro-síntese}

\begin{tabular}{|c|c|c|}
\hline Passo & Distância & Grupos \\
\hline 1 & $\mathrm{~d}_{4,20}=0,03$ & $1,2,3,(4,20), 5,6,7,8,9,10,11,12,13,14,15,16,17,18,19$ \\
\hline 2 & $\mathrm{~d}_{6,14}=0,1$ & $1,2,3,(4,20), 5,(6,14), 7,8,9,10,11,12,13,15,16,17,18,19$ \\
\hline 3 & $\mathrm{~d}_{(4,20), 2}=0,165$ & $1,(4,20,2), 3,5,(6,14), 7,8,9,10,11,12,13,15,16,17,18,19$ \\
\hline 4 & $\mathrm{~d}_{(16,17)}=0,17$ & $1,(4,20,2), 3,5,(6,14), 7,8,9,10,11,12,13,15,(16,17), 18,19$ \\
\hline 5 & $\mathrm{~d}_{(1,13)}=0,25$ & $(1,13),(4,20,2), 3,5,(6,14), 7,8,9,10,11,12,15,(16,17), 18,19$ \\
\hline 6 & $\mathrm{~d}_{(10,11)}=1,0012$ & $(1,13),(4,20,2), 3,5,(6,14), 7,8,9,(10,11), 12,15,(16,17), 18,19$ \\
\hline 7 & $\mathrm{~d}_{(6,14) \mathrm{e}}=1,0012$ & $(1,13),(4,20,2), 3,5,(6,14,8), 7,9,(10,11), 12,15,(16,17), 18,19$ \\
\hline
\end{tabular}




\section{8. ${ }^{a}$ MATRIZ DE DISTÂNCIAS}

\section{Recálculo para o $7^{\circ}$ Agrupamento — Critério $\rightarrow$ Média entre grupos}

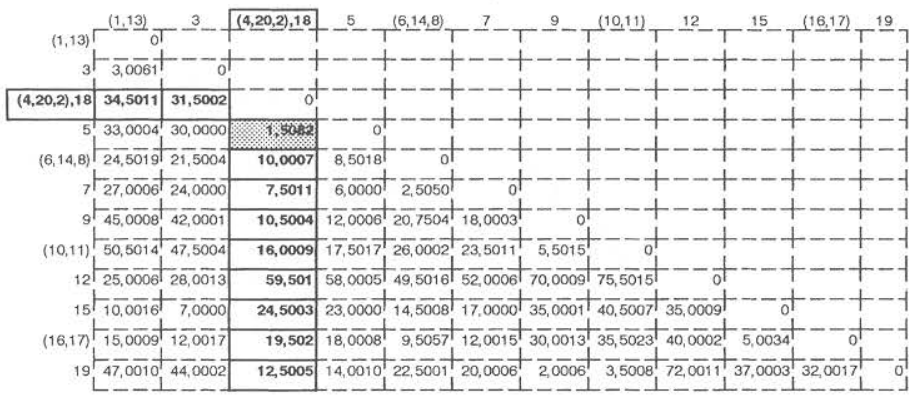

\section{8..$^{\circ}$ Quadro -síntese}

\begin{tabular}{|c|c|c|}
\hline Passo & Distância & Grupos \\
\hline 1 & $\mathrm{~d}_{4,20}=0,03$ & $1,2,3,(4,20), 5,6,7,8,9,10,11,12,13,14,15,16,17,18,19$ \\
\hline 2 & $\mathrm{~d}_{6,14}=0,1$ & $1,2,3,(4,20), 5,(6,14), 7,8,9,10,11,12,13,15,16,17,18,19$ \\
\hline 3 & $\mathrm{~d}_{(4,20), 2}=0,165$ & $1,(4,20,2), 3,5,(6,14), 7,8,9,10,11,12,13,15,16,17,18,19$ \\
\hline 4 & $\mathrm{~d}_{(16,17)}=0,17$ & $1,(4,20,2), 3,5,(6,14), 7,8,9,10,11,12,13,15,(16,17), 18,19$ \\
\hline 5 & $\mathrm{~d}_{(1,13)}=0,25$ & $(1,13),(4,20,2), 3,5,(6,14), 7,8,9,10,11,12,15,(16,17), 18,19$ \\
\hline 6 & $\mathrm{~d}_{(19,11)}=1,0012$ & $(1,13),(4,20,2), 3,5,(6,14), 7,8,9,(10,11), 12,15,(16,17), 18,19$ \\
\hline 7 & $\mathrm{~d}_{(6,14), 8}=1,0012$ & $(1,13),(4,20,2), 3,5,(6,14,8), 7,9,(10,11), 12,15,(16,17), 18,19$ \\
\hline 8 & $\mathrm{~d}_{(4,20,2), 18}=1,0121$ & $(1,13),(4,20,2,18), 3,5,(6,14,8), 7,9,(10,11), 12,15,(16,17), 19$ \\
\hline
\end{tabular}

\section{9. ${ }^{a}$ MATRIZ DE DISTÂNCIAS}

\section{Recálculo para o 8. ${ }^{\circ}$ Agrupamento - Critério $\rightarrow$ Média entre grupos}

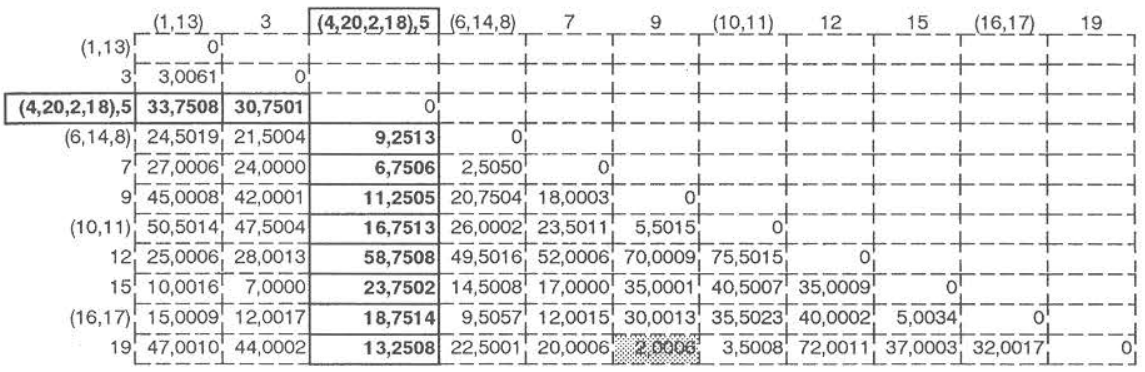

\section{Quadro-síntese}

\begin{tabular}{|c|c|c|}
\hline Passo & Distância & Grupos \\
\hline 1 & $\mathrm{~d}_{4,20}=0,03$ & $1,2,3,(4,20), 5,6,7,8,9,10,11,12,13,14,15,16,17,18,19$ \\
\hline 2 & $\mathrm{~d}_{6,14}=0,1$ & $1,2,3,(4,20), 5,(6,14), 7,8,9,10,11,12,13,15,16,17,18,19$ \\
\hline 3 & $\mathrm{~d}_{(4,20), 2}=0,165$ & $1,(4,20,2), 3,5,(6,14), 7,8,9,10,11,12,13,15,16,17,18,19$ \\
\hline 4 & $\mathrm{~d}_{(1,6,17)}=0,17$ & $1,(4,20,2), 3,5,(6,14), 7,8,9,10,11,12,13,15,(16,17), 18,19$ \\
\hline 5 & $\mathrm{~d}_{(1,13)}=0,25$ & $(1,13),(4,20,2), 3,5,(6,14), 7,8,9,10,11,12,15,(16,17), 18,19$ \\
\hline 6 & $\mathrm{~d}_{(10,11)}=1,0012$ & $(1,13),(4,20,2), 3,5,(6,14), 7,8,9,(10,11), 12,15,(16,17), 18,19$ \\
\hline 7 & $\mathrm{~d}_{(6,14), 8}=1,0012$ & $(1,13),(4,20,2), 3,5,(6,14,8), 7,9,(10,11), 12,15,(16,17), 18,19$ \\
\hline 8 & $\mathrm{~d}_{(4,20,2), 18}=1,0121$ & $(1,13),(4,20,2,18), 3,5,(6,14,8), 7,9,(10,11), 12,15,(16,17), 19$ \\
\hline 9 & $\mathrm{~d}_{(4,20,2,18), 5}=1,5082$ & $(1,13),(4,20,2,18,5), 3,(6,14,8), 7,9,(10,11), 12,15,(16,17), 19$ \\
\hline
\end{tabular}




\section{0. ${ }^{a}$ MATRIZ DE DISTÂNCIAS}

\section{Recálculo para o 9. Agrupamento - Critério $\rightarrow$ Média entre grupos}

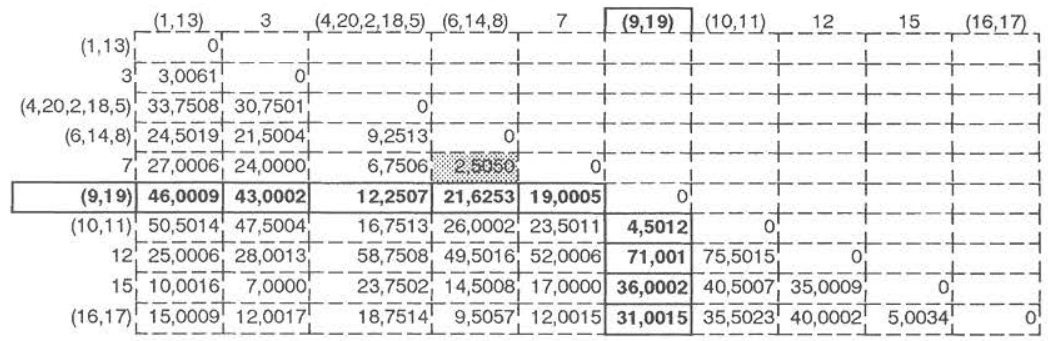

10. ${ }^{\circ}$ Quadro-síntese

\begin{tabular}{|c|c|c|}
\hline Passo & Distância & Grupos \\
\hline 1 & $\mathrm{~d}_{4,20}=0,03$ & $1,2,3,(4,20), 5,6,7,8,9,10,11,12,13,14,15,16,17,18,19$ \\
\hline 2 & $\mathrm{~d}_{6,14}=0,1$ & $1,2,3,(4,20), 5,(6,14), 7,8,9,10,11,12,13,15,16,17,18,19$ \\
\hline 3 & $\mathrm{~d}_{(4,20), 2}=0,165$ & $1,(4,20,2), 3,5,(6,14), 7,8,9,10,11,12,13,15,16,17,18,19$ \\
\hline 4 & $\mathrm{~d}_{(16,17}=0,17$ & $1,(4,20,2), 3,5,(6,14), 7,8,9,10,11,12,13,15,(16,17), 18,19$ \\
\hline 5 & $\mathrm{~d}_{(1,13)}=0,25$ & $(1,13),(4,20,2), 3,5,(6,14), 7,8,9,10,11,12,15,(16,17), 18,19$ \\
\hline 6 & $\mathrm{~d}_{(10,1) 1,}=1,0012$ & $(1,13),(4,20,2), 3,5,(6,14), 7,8,9,(10,11), 12,15,(16,17), 18,19$ \\
\hline 7 & $\mathrm{~d}_{(6,14), 8}=1,0012$ & $(1,13),(4,20,2), 3,5,(6,14,8), 7,9,(10,11), 12,15,(16,17), 18,19$ \\
\hline 8 & $\mathrm{~d}_{(4,20,2), 18}=1,0121$ & $(1,13),(4,20,2,18), 3,5,(6,14,8), 7,9,(10,11), 12,15,(16,17), 19$ \\
\hline 9 & $\mathrm{~d}_{(4,20,2,18,5}=1,5082$ & $(1,13),(4,20,2,18,5), 3,(6,14,8), 7,9,(10,11), 12,15,(16,17), 19$ \\
\hline 10 & $\mathrm{~d}_{(9,19)}=2,0006$ & $(1,13),(4,20,2,18,5), 3,(6,14,8), 7,(9,19),(10,11), 12,15,(16,17)$ \\
\hline
\end{tabular}

\section{1. ${ }^{a}$ MATRIZ DE DISTÂNCIAS}

Recálculo para o $10 .^{\circ}$ Agrupamento - Critério $\rightarrow$ Média entre grupos

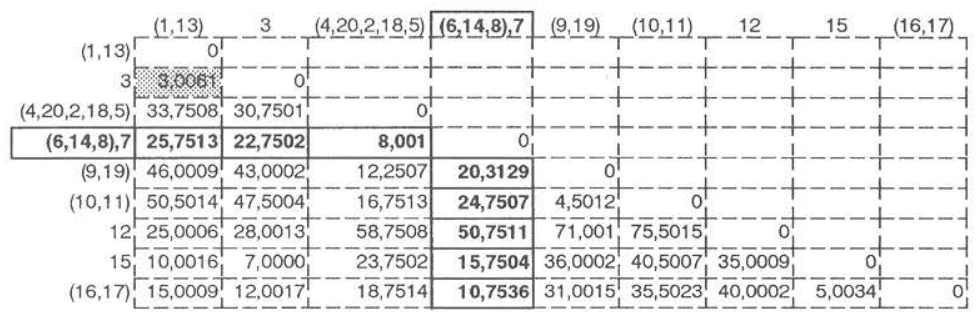

11. ${ }^{\circ}$ Quadro-síntese

\begin{tabular}{|c|c|c|}
\hline Passo & Distância & Grupos \\
\hline 1 & $\mathrm{~d}_{4,20}=0,03$ & $1,2,3,(4,20), 5,6,7,8,9,10,11,12,13,14,15,16,17,18,19$ \\
\hline 2 & $\mathrm{~d}_{6,14}=0,1$ & $1,2,3,(4,20), 5,(6,14), 7,8,9,10,11,12,13,15,16,17,18,19$ \\
\hline 3 & $\mathrm{~d}_{(4,20), 2}=0,165$ & $1,(4,20,2), 3,5,(6,14), 7,8,9,10,11,12,13,15,16,17,18,19$ \\
\hline 4 & $\mathrm{~d}_{(16,17)}=0,17$ & $1,(4,20,2), 3,5,(6,14), 7,8,9,10,11,12,13,15,(16,17), 18,19$ \\
\hline 5 & $\mathrm{~d}_{(1,13)}=0,25$ & $(1,13),(4,20,2), 3,5,(6,14), 7,8,9,10,11,12,15,(16,17), 18,19$ \\
\hline 6 & $\mathrm{~d}_{(10,11)}=1,0012$ & $(1,13),(4,20,2), 3,5,(6,14), 7,8,9,(10,11), 12,15,(16,17), 18,19$ \\
\hline 7 & $\mathrm{~d}_{(6,14), 8}=1,0012$ & $(1,13),(4,20,2), 3,5,(6,14,8), 7,9,(10,11), 12,15,(16,17), 18,19$ \\
\hline 8 & $\mathrm{~d}_{(4,20,2), 18}=1,0121$ & $(1,13),(4,20,2,18), 3,5,(6,14,8), 7,9,(10,11), 12,15,(16,17), 19$ \\
\hline 9 & $\mathrm{~d}_{(4,20,2,18), 5}=1,5082$ & $(1,13),(4,20,2,18,5), 3,(6,14,8), 7,9,(10,11), 12,15,(16,17), 19$ \\
\hline 10 & $\mathrm{~d}_{(2,19)}=2,0006$ & $(1,13),(4,20,2,18,5), 3,(6,14,8), 7,(9,19),(10,11), 12,15,(16,17)$ \\
\hline 11 & $\mathrm{~d}_{(6,14,8), 7}=2,505$ & $(1,13),(4,20,2,18,5), 3,(6,14,8,7),(9,19),(10,11), 12,15,(16,17)$ \\
\hline
\end{tabular}




\section{2. a MATRIZ DE DISTÂNCIAS}

Recálculo para o 11..$^{\circ}$ Agrupamento - Critério $\rightarrow$ Média entre grupos

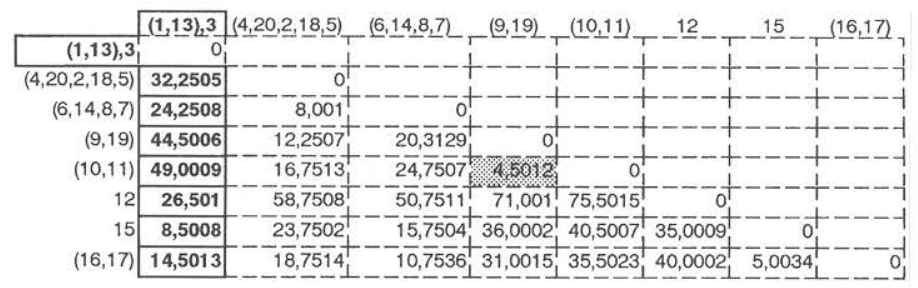

\section{2. ${ }^{\circ}$ Quadro-síntese}

\begin{tabular}{|c|c|c|}
\hline Passo & Distância & Grupos \\
\hline 1 & $\mathrm{~d}_{4,20}=0,03$ & $1,2,3,(4,20), 5,6,7,8,9,10,11,12,13,14,15,16,17,18,19$ \\
\hline 2 & $\mathrm{~d}_{6,14}=0,1$ & $1,2,3,(4,20), 5,(6,14), 7,8,9,10,11,12,13,15,16,17,18,19$ \\
\hline 3 & $\mathrm{~d}_{(4,20), 2}=0,165$ & $1,(4,20,2), 3,5,(6,14), 7,8,9,10,11,12,13,15,16,17,18,19$ \\
\hline 4 & $\mathrm{~d}_{(16,1)}=0,17$ & $1,(4,20,2), 3,5,(6,14), 7,8,9,10,11,12,13,15,(16,17), 18,19$ \\
\hline 5 & $\mathrm{~d}_{(11,13)}=0,25$ & $(1,13),(4,20,2), 3,5,(6,14), 7,8,9,10,11,12,15,(16,17), 18,19$ \\
\hline 6 & $\mathrm{~d}_{(10,11)}=1,0012$ & $(1,13),(4,20,2), 3,5,(6,14), 7,8,9,(10,11), 12,15,(16,17), 18,19$ \\
\hline 7 & $\mathrm{~d}_{(6,144),}=1,0012$ & $(1,13),(4,20,2), 3,5,(6,14,8), 7,9,(10,11), 12,15,(16,17), 18,19$ \\
\hline 8 & $\mathrm{~d}_{(4,20,2), 18}=1,0121$ & $(1,13),(4,20,2,18), 3,5,(6,14,8), 7,9,(10,11), 12,15,(16,17), 19$ \\
\hline 9 & $\mathrm{~d}_{(4,20,218), 5}=1,5082$ & $(1,13),(4,20,2,18,5), 3,(6,14,8), 7,9,(10,11), 12,15,(16,17), 19$ \\
\hline 10 & $\mathrm{~d}_{(9,19)}=2,0006$ & $(1,13),(4,20,2,18,5), 3,(6,14,8), 7,(9,19),(10,11), 12,15,(16,17)$ \\
\hline 11 & $\mathrm{~d}_{(6,148), 7}=2,505$ & $(1,13),(4,20,2,18,5), 3,(6,14,8,7),(9,19),(10,11), 12,15,(16,17)$ \\
\hline 12 & $\mathrm{~d}_{(1,13), 3}=3,0061$ & $(1,13,3),(4,20,2,18,5),(6,14,8,7),(9,19),(10,11), 12,15,(16,17)$ \\
\hline
\end{tabular}

\section{3. ${ }^{a}$ MATRIZ DE DISTÂNCIAS}

Recálculo para o $12 .^{\circ}$ Agrupamento - Critério $\rightarrow$ Média entre grupos

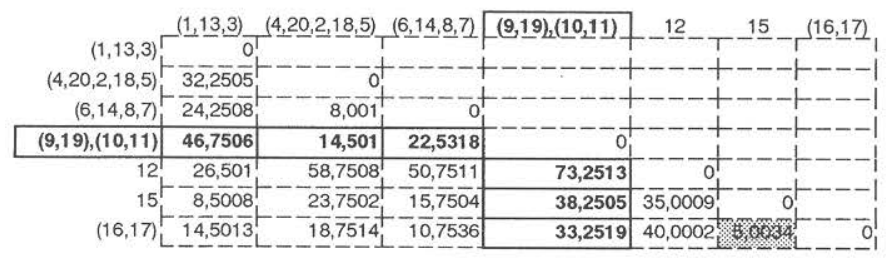

\section{3. ${ }^{\circ}$ Quadro-síntese}

\begin{tabular}{|c|c|c|}
\hline Passo & Distância & Grupos \\
\hline 1 & $\mathrm{~d}_{4,20}=0,03$ & $1,2,3,(4,20), 5,6,7,8,9,10,11,12,13,14,15,16,17,18,19$ \\
\hline 2 & $\mathrm{~d}_{6,14}=0,1$ & $1,2,3,(4,20), 5,(6,14), 7,8,9,10,11,12,13,15,16,17,18,19$ \\
\hline 3 & $\mathrm{~d}_{(4,20), 2}=0,165$ & $1,(4,20,2), 3,5,(6,14), 7,8,9,10,11,12,13,15,16,17,18,19$ \\
\hline 4 & $\mathrm{~d}_{(1,3,1)}=0,17$ & $1,(4,20,2), 3,5,(6,14), 7,8,9,10,11,12,13,15,(16,17), 18,19$ \\
\hline 5 & $\mathrm{~d}_{(1,13)}=0,25$ & $(1,13),(4,20,2), 3,5,(6,14), 7,8,9,10,11,12,15,(16,17), 18,19$ \\
\hline 6 & $\mathrm{~d}_{(10,11)}=1,0012$ & $(1,13),(4,20,2), 3,5,(6,14), 7,8,9,(10,11), 12,15,(16,17), 18,19$ \\
\hline 7 & $\mathrm{~d}_{(6,14), 8}=1,0012$ & $(1,13),(4,20,2), 3,5,(6,14,8), 7,9,(10,11), 12,15,(16,17), 18,19$ \\
\hline 8 & $\mathrm{~d}_{(4,20,2), 18}=1,0121$ & $(1,13),(4,20,2,18), 3,5,(6,14,8), 7,9,(10,11), 12,15,(16,17), 19$ \\
\hline 9 & $\mathrm{~d}_{(4,20,218), 5}=1,5082$ & $(1,13),(4,20,2,18,5), 3,(6,14,8), 7,9,(10,11), 12,15,(16,17), 19$ \\
\hline 10 & $\mathrm{~d}_{(9,19)}=2,0006$ & $(1,13),(4,20,2,18,5), 3,(6,14,8), 7,(9,19),(10,11), 12,15,(16,17)$ \\
\hline 11 & $\mathrm{~d}_{(6,148), 7}=2,505$ & $(1,13),(4,20,2,18,5), 3,(6,14,8,7),(9,19),(10,11), 12,15,(16,17)$ \\
\hline 12 & $\mathrm{~d}_{(1,13), 3}=3,0061$ & $(1,13,3),(4,20,2,18,5),(6,14,8,7),(9,19),(10,11), 12,15,(16,17)$ \\
\hline 13 & $\mathrm{~d}_{(9,19),(10,11)}=4,5012$ & $(1,13,3),(4,20,2,18,5),(6,14,8,7),(9,19,10,11), 12,15,(16,17)$ \\
\hline
\end{tabular}


14. a MATRIZ DE DISTÂNCIAS

Recálculo para o $13 .^{\circ}$ Agrupamento — Critério $\rightarrow$ Média entre grupos

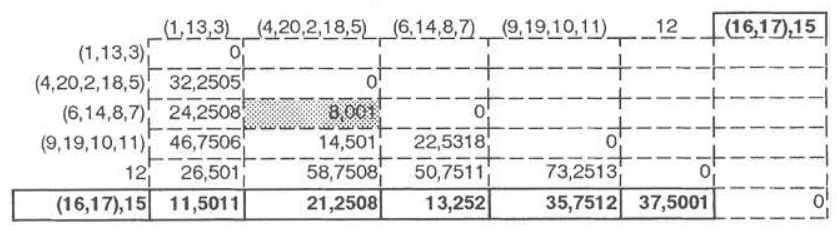

14. ${ }^{\circ}$ Quadro-síntese

\begin{tabular}{|c|c|c|}
\hline Passo & Distância & Grupos \\
\hline 1 & $\mathrm{~d}_{4,20}=0,03$ & $1,2,3,(4,20), 5,6,7,8,9,10,11,12,13,14,15,16,17,18,19$ \\
\hline 2 & $\mathrm{~d}_{6,14}=0,1$ & $1,2,3,(4,20), 5,(6,14), 7,8,9,10,11,12,13,15,16,17,18,19$ \\
\hline 3 & $\mathrm{~d}_{(4,202,2}=0,165$ & $1,(4,20,2), 3,5,(6,14), 7,8,9,10,11,12,13,15,16,17,18,19$ \\
\hline 4 & $\mathrm{~d}_{(16,17)}=0,17$ & $1,(4,20,2), 3,5,(6,14), 7,8,9,10,11,12,13,15,(16,17), 18,19$ \\
\hline 5 & $\mathrm{~d}_{(1,13)}=0,25$ & $(1,13),(4,20,2), 3,5,(6,14), 7,8,9,10,11,12,15,(16,17), 18,19$ \\
\hline 6 & $\mathrm{~d}_{(10,11)}=1,0012$ & $(1,13),(4,20,2), 3,5,(6,14), 7,8,9,(10,11), 12,15,(16,17), 18,19$ \\
\hline 7 & $\mathrm{~d}_{(6,14),}=1,0012$ & $(1,13),(4,20,2), 3,5,(6,14,8), 7,9,(10,11), 12,15,(16,17), 18,19$ \\
\hline 8 & $\mathrm{~d}_{(4,20,2), 18}=1,0121$ & $(1,13),(4,20,2,18), 3,5,(6,14,8), 7,9,(10,11), 12,15,(16,17), 19$ \\
\hline 9 & $\mathrm{~d}_{(4,20,218), 5}=1,5082$ & $(1,13),(4,20,2,18,5), 3,(6,14,8), 7,9,(10,11), 12,15,(16,17), 19$ \\
\hline 10 & $\mathrm{~d}_{(9,19)}=2,0006$ & $(1,13),(4,20,2,18,5), 3,(6,14,8), 7,(9,19),(10,11), 12,15,(16,17)$ \\
\hline 11 & $\mathrm{~d}_{(6,148), 7}=2,505$ & $(1,13),(4,20,2,18,5,3,(6,14,8,7),(9,19),(10,11), 12,15,(16,17)$ \\
\hline 12 & $\mathrm{~d}_{(1,13), 3}=3,0061$ & $(1,13,3),(4,20,2,18,5),(6,14,8,7),(9,19),(10,11), 12,15,(16,17)$ \\
\hline 13 & $\mathrm{~d}_{(9,192)(10,11)}=4,5012$ & $(1,13,3),(4,20,2,18,5),(6,14,8,7),(9,19,10,11), 12,15,(16,17)$ \\
\hline 14 & $\mathrm{~d}_{(16,17,15}=5,0034$ & $(1,13,3),(4,20,2,18,5),(6,14,8,7),(9,19,10,11), 12,(16,17,15)$ \\
\hline
\end{tabular}

\section{5. ${ }^{\text {a }}$ MATRIZ DE DISTÂNCIAS}

Recálculo para o $14 .^{\circ}$ Agrupamento - Critério $\rightarrow$ Média entre grupos

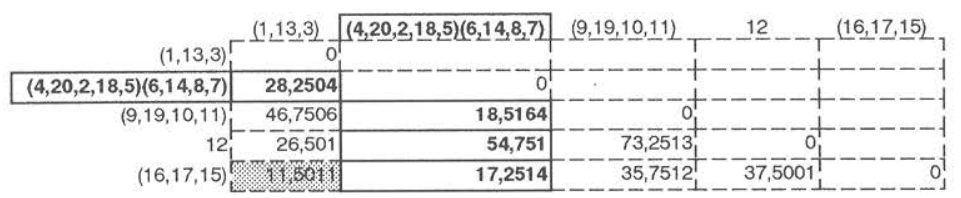

15. Q Quadro-síntese

\begin{tabular}{|c|c|c|}
\hline Passo & Distância & Grupos \\
\hline 1 & $d_{4,20}=0,03$ & $1,2,3,(4,20), 5,6,7,8,9,10,11,12,13,14,15,16,17,18,19$ \\
\hline 2 & $d_{6,14}=0,1$ & $1,2,3,(4,20), 5,(6,14), 7,8,9,10,11,12,13,15,16,17,18,19$ \\
\hline 3 & $d_{(4,20), 2}=0,165$ & $1,(4,20,2), 3,5,(6,14), 7,8,9,10,11,12,13,15,16,17,18,19$ \\
\hline 4 & $d_{(16,17)}=0,17$ & $1,(4,20,2), 3,5,(6,14), 7,8,9,10,11,12,13,15,(16,17), 18,19$ \\
\hline 5 & $\mathrm{~d}_{(1,13)}=0,25$ & $(1,13),(4,20,2), 3,5,(6,14), 7,8,9,10,11,12,15,(16,17), 18,19$ \\
\hline 6 & $\mathrm{~d}_{(10,11)}=1,0012$ & $(1,13),(4,20,2), 3,5,(6,14), 7,8,9,(10,11), 12,15,(16,17), 18,19$ \\
\hline 7 & $\mathrm{~d}_{(6,14), 8=1,0012}$ & $(1,13),(4,20,2), 3,5,(6,14,8), 7,9,(10,11), 12,15,(16,17), 18,19$ \\
\hline 8 & $d_{(4,20,2), 18}=1,0121$ & $(1,13),(4,20,2,18), 3,5,(6,14,8), 7,9,(10,11), 12,15,(16,17), 19$ \\
\hline 9 & $d_{(4,20,218), 5}=1,5082$ & $(1,13),(4,20,2,18,5), 3,(6,14,8), 7,9,(10,11), 12,15,(16,17), 19$ \\
\hline 10 & $d_{(9,19)}=2,0006$ & $(1,13),(4,20,2,18,5), 3,(6,14,8), 7,(9,19),(10,11), 12,15,(16,17)$ \\
\hline 11 & $d_{(6,148) 7}=2,505$ & $(1,13),(4,20,2,18,5), 3,(6,14,8,7),(9,19),(10,11), 12,15,(16,17)$ \\
\hline 12 & $d_{(1,13), 3}=3,0061$ & $(1,13,3),(4,20,2,18,5),(6,14,8,7),(9,19),(10,11), 12,15,(16,17)$ \\
\hline 13 & $\mathrm{~d}_{(9,19)(10,11)}=4,5012$ & $(1,13,3),(4,20,2,18,5),(6,14,8,7),(9,19,10,11), 12,15,(16,17)$ \\
\hline 14 & $\mathrm{~d}_{(16,17), 16}=5,0034$ & $(1,13,3),(4,20,2,18,5),(6,14,8,7),(9,19,10,11), 12,(16,17,15)$ \\
\hline 15 & $\mathrm{~d}_{(4,20,218,5)(6,14,8,7)}=8,001$ & $(1,13,3),(4,20,2,18,5,6,14,8,7),(9,19,10,11), 12,(16,17,15)$ \\
\hline
\end{tabular}




\section{6. ${ }^{a}$ MATRIZ DE DISTÂNCIAS}

Recálculo para o $15 .^{\circ}$ Agrupamento - Critério $\rightarrow$ Média entre grupos

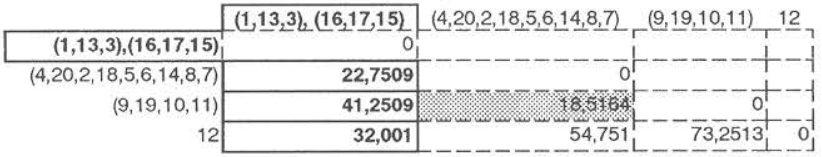

\section{6. ${ }^{\circ}$ Quadro-síntese}

\begin{tabular}{|c|c|c|}
\hline Passo & Distância & Grupos \\
\hline 1 & $d_{4,20}=0,03$ & $1,2,3,(4,20), 5,6,7,8,9,10,11,12,13,14,15,16,17,18,19$ \\
\hline 2 & $d_{6,14}=0,1$ & $1,2,3,(4,20), 5,(6,14), 7,8,9,10,11,12,13,15,16,17,18,19$ \\
\hline 3 & $d_{(4,20), 2}=0,165$ & $1,(4,20,2), 3,5,(6,14), 7,8,9,10,11,12,13,15,16,17,18,19$ \\
\hline 4 & $d_{116,17}=0,17$ & $1,(4,20,2), 3,5,(6,14), 7,8,9,10,11,12,13,15,(16,17), 18,19$ \\
\hline 5 & $d_{(1,13)}=0,25$ & $(1,13),(4,20,2), 3,5,(6,14), 7,8,9,10,11,12,15,(16,17), 18,19$ \\
\hline 6 & $d_{(10,11)}=1,0012$ & $(1,13),(4,20,2), 3,5,(6,14), 7,8,9,(10,11), 12,15,(16,17), 18,19$ \\
\hline 7 & $d_{(6,14), 8}=1,0012$ & $(1,13),(4,20,2), 3,5,(6,14,8), 7,9,(10,11), 12,15,(16,17), 18,19$ \\
\hline 8 & $d_{(4,20,2), 18}=1,0121$ & $(1,13),(4,20,2,18), 3,5,(6,14,8), 7,9,(10,11), 12,15,(16,17), 19$ \\
\hline 9 & $d_{(4,20,218), 5}=1,5082$ & $(1,13),(4,20,2,18,5), 3,(6,14,8), 7,9,(10,11), 12,15,(16,17), 19$ \\
\hline 10 & $\mathrm{~d}_{(9,19)}=2,0006$ & $(1,13),(4,20,2,18,5), 3,(6,14,8), 7,(9,19),(10,11), 12,15,(16,17)$ \\
\hline 11 & $d_{(6,448), 7}=2,505$ & $(1,13),(4,20,2,18,5), 3,(6,14,8,7),(9,19),(10,11), 12,15,(16,17)$ \\
\hline 12 & $d_{(1,13), 3}=3,0061$ & $(1,13,3),(4,20,2,18,5),(6,14,8,7),(9,19),(10,11), 12,15,(16,17)$ \\
\hline 13 & $d_{(9,19)(10,11)}=4,5012$ & $(1,13,3),(4,20,2,18,5),(6,14,8,7),(9,19,10,11), 12,15,(16,17)$ \\
\hline 14 & $\mathrm{~d}_{(16,17,15}=5,0034$ & $(1,13,3),(4,20,2,18,5),(6,14,8,7),(9,19,10,11), 12,(16,17,15)$ \\
\hline 15 & $d_{(4,20,218,5)(6,14,8,7)}=8,001$ & $(1,13,3),(4,20,2,18,5,6,14,8,7),(9,19,10,11), 12,(16,17,15)$ \\
\hline 16 & $d_{(1,13,3),(16,17,15)}=11,5011$ & $(1,13,3,16,17,15),(4,20,2,18,5,6,14,8,7),(9,19,10,11), 12$ \\
\hline
\end{tabular}

\section{7. a MATRIZ DE DISTÂNCIAS}

Recálculo para o 16. Agrupamento - Critério $\rightarrow$ Média entre grupos

\begin{tabular}{|c|c|c|}
\hline$(1) 31617151$ & $\left.\Gamma^{(1,13}, 3,16,17,15\right)$ & $(4,20,2,18,5,6,14,8,7),(9,19,10,11)$ \\
\hline$(4,20,2,18,5,6,14,8,7),(9,19,10,11)$ & 32,006 & 0 \\
\hline 12 & 32,001 & 64,0012 \\
\hline
\end{tabular}

\section{Quadro-síntese}

\begin{tabular}{|c|c|c|}
\hline Passo & Distância & Grupos \\
\hline 1 & $d_{4,20}=0,03$ & $1,2,3,(4,20), 5,6,7,8,9,10,11,12,13,14,15,16,17,18,19$ \\
\hline 2 & $d_{6,14}=0,1$ & $1,2,3,(4,20), 5,(6,14), 7,8,9,10,11,12,13,15,16,17,18,19$ \\
\hline 3 & $d_{(4,20), 2}=0,165$ & $1,(4,20,2), 3,5,(6,14), 7,8,9,10,11,12,13,15,16,17,18,19$ \\
\hline 4 & $\mathrm{~d}_{(16,17)}=0,17$ & $1,(4,20,2), 3,5,(6,14), 7,8,9,10,11,12,13,15,(16,17), 18,19$ \\
\hline 5 & $d_{(1,13)}=0,25$ & $(1,13),(4,20,2), 3,5,(6,14), 7,8,9,10,11,12,15,(16,17), 18,19$ \\
\hline 6 & $d_{(10,11)}=1,0012$ & $(1,13),(4,20,2), 3,5,(6,14), 7,8,9,(10,11), 12,15,(16,17), 18,19$ \\
\hline 7 & $d_{(6,14), 8}=1,0012$ & $(1,13),(4,20,2), 3,5,(6,14,8), 7,9,(10,11), 12,15,(16,17), 18,19$ \\
\hline 8 & $d_{(4,20,22,18}=1,0121$ & $(1,13),(4,20,2,18), 3,5,(6,14,8), 7,9,(10,11), 12,15,(16,17), 19$ \\
\hline 9 & $d_{(4,20,218), 5}=1,5082$ & $(1,13),(4,20,2,18,5), 3,(6,14,8), 7,9,(10,11), 12,15,(16,17), 19$ \\
\hline 10 & $d_{(2,19)}=2,0006$ & $(1,13),(4,20,2,18,5), 3,(6,14,8), 7,(9,19),(10,11), 12,15,(16,17)$ \\
\hline 11 & $d_{(6,148), 7}=2,505$ & $(1,13),(4,20,2,18,5), 3,(6,14,8,7),(9,19),(10,11), 12,15,(16,17)$ \\
\hline 12 & $d_{(1,13), 3}=3,0061$ & $(1,13,3),(4,20,2,18,5),(6,14,8,7),(9,19),(10,11), 12,15,(16,17)$ \\
\hline 13 & $d_{(9,19)(10,11)}=4,5012$ & $(1,13,3),(4,20,2,18,5),(6,14,8,7),(9,19,10,11), 12,15,(16,17)$ \\
\hline 14 & $d_{116,17,15}=5,0034$ & $(1,13,3),(4,20,2,18,5),(6,14,8,7),(9,19,10,11), 12,(16,17,15)$ \\
\hline 15 & $\mathrm{~d}_{(4,20,2,18,5)(6,14,8,7)}=8,001$ & $(1,13,3),(4,20,2,18,5,6,14,8,7),(9,19,10,11), 12,(16,17,15)$ \\
\hline 16 & $d_{(1,13,3),(16,17,15)}=11,5011$ & $(1,13,3,16,17,15),(4,20,2,18,5,6,14,8,7),(9,19,10,11), 12$ \\
\hline 17 & $d_{(4,20,2,18,5,6,14,8,7)(9,19,10,11)}=18,5164$ & $(1,13,3,16,17,15),(4,20,2,18,5,6,14,8,7,9,19,10,11), 12$ \\
\hline
\end{tabular}

